[Agr. Biol. Chem., Vol. 27, No. 10, p. 695 699, 1963]

\title{
Total Synthesis of Nodakenetin and Marmesin
}

\author{
By Minoru Nakajima, Junichi Oda and Hiroshi Fukami \\ Department of Agricultural Chemistry, Kyoto University, Kyoto \\ Received June 24, 1963
}

\begin{abstract}
Nodakenetin and marmesin were synthesized from $\beta$-resorcylaldehyde through 2 -( $\alpha$-hydroxyisopropyl)-6-hydroxycoumaran.
\end{abstract}

Nodakenetin (VIf) $\quad\left([a]_{D}-22.4^{\circ}\right.$, m.p. $186.5^{\circ} \mathrm{C}$ ) was found by $\mathrm{J}$. Arima ${ }^{1)}$ in 1929 as the aglycon of nodakenin, isolated from Peucedanum decursiurm Maxim (Nodake) and its structure was proposed by E. Späth and E. Tyray ${ }^{2)}$ to be 2'-(a-hydroxyisopropyl) -2',3'-dihydro-6,7-furanocoumarin. Marmesin $\left([a]_{\mathrm{D}}^{34}\right.$ $+26.8^{\circ}$, m.p. $189^{\circ} \mathrm{C}$ ) was isolated by A. Chatterjee and S. S. Mitra ${ }^{3:}$ in 1949 from the bark of Aegle marmelos, Correâ (Rutaceae). They reported that marmesin might be the optical antipode of (-)-nodakenetin, and this was supported by Mustafa and Fayez ${ }^{4}$ who also isolated marmesin from the fruits of $A m m i$ majus $^{4,5)}$. In this paper, we describe the total synthesis of both substances.

$\beta$-Resorcylaldehyde (Ia) was obtained by condensation of resorcinol with formic acid, using borotrifluoride as a catalyst, and converted to benzyl ether (Ib). Methyl 6-benzyloxycoumarone-2-carboxylate (IIa) was synthesized by the following two methods: one ${ }^{6)}$ is the methylation of coumarone-2-carboxylic acid (IIb), which was derived from Ib by conden-

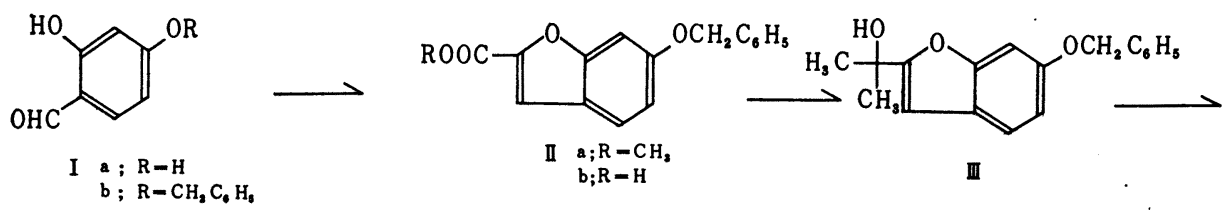<smiles>[R]C(C)(C)C1Cc2ccc(O)cc2O1</smiles>

IV $\quad \underset{a}{a ;} \mathrm{R}-\mathrm{H}$<smiles>[R10]c1cc2c(cc1C=O)CC(C([R])(C)C)O2</smiles>

V a; $\mathrm{R}-\mathrm{H}, \mathrm{R}_{1}-\mathrm{H}$ b; $\mathrm{R}-\mathrm{OH}, \mathrm{R}_{1}-\mathrm{H}$ $\mathrm{C} ; \mathrm{R}-\mathrm{H}, \mathrm{R}_{2}-\mathrm{COCH}_{2}$<smiles>[R1]C1=Cc2cc3c(OC)c(c2OC1O)OC(C([R])(C)CCC)C3</smiles>

V a $\mathrm{R}-\mathrm{H}, \mathrm{R}_{1}-\mathrm{COOC}_{2} \mathrm{H}_{4}$ $b ; R-H, R_{1}-C N$ c; $\mathrm{R}-\mathrm{H}, \mathrm{R}_{1}=\mathrm{COOH}$ d; $\mathrm{R}-\mathrm{H}, \mathrm{R}_{1}-\mathrm{H}$ e; $\mathrm{R}-\mathrm{OH}, \mathrm{R}_{1}=\mathrm{COOH}$ $f ; R=O H, R_{1}=H$

FIG. 1.

1) J. Arima, Bull. Chem. Soc. Japan, 4, 16, 113 (1929).

2) E. Späth and E. Tyray, Ber., 72, 2089 (1939).

3) A. Chatterjee and S.S. Mitra, J. Am. Chem. Soc., 71, 606 (1949).
4) E.A. Abu-Mustafa and M.B.E. Fayez, J. Org. Chem., 26, 161 (1961).

5) N.A. Starkowsky and N. Bardran, ibid., 23, 1818 (1958)

6) S. Tanaka, J. Am. Chem. Soc., 73, 872 (1951). 
sation with ethyl bromomalonate, and the other ${ }^{7)}$ is the cyclization of methyl 2-formyl-5benzyloxyphenoxyacetate with magnesium methoxide, which was derived from Ib with methyl bromoacetate. The coumarone (IIa) was treated with 3 moles of $\mathrm{CH}_{3} \mathrm{MgI}$ to give 2- (a-hydroxyisopropyl) -6-benzyloxycoumarone $(\mathrm{III})^{8)}$. In the IR-spectrum of this compound, $\mathrm{OH}$-absorption band is distinctly observed at $3300 \mathrm{~cm}^{-1}$. This compound is, however, very unstable with a trace of acid and easily converted even by standing at room temperature to an unknown substance melting at $58 \sim 61^{\circ} \mathrm{C}$. Then we tried hydrogenation of the coumarone (III) with various catalysts in ethanol, after passing it through aluminium oxide column. First, hydrogenation was carried out using Adams' platinum oxide or palladium-barium sulphate as a catalyst, but in these cases only starting material was recovered. On catalytic hydrogenation over palladium charcoal ${ }^{9}$, the coumarone (III) absorbed just 3 moles of hydrogen to give 2-isopropyl-6-hydroxycoumaran (IVa $)^{8)}$, m.p. $79^{\circ} \mathrm{C}$. However, in the presence of palladium charcoal $^{9)}$ treated with alkali, the same compound (III) absorbed just 2 moles of hydrogen and gave rise to 2 -( $a$-hydroxyisopropyl)6-hydroxycoumaran (IVb), m.p. 158 9 ${ }^{\circ} \mathrm{C}$. This compound was also obtained on hydrogenation with Raney's Nickel under 80 atm. in room temperature.

The coumarans (IVa, IVb) were formylated by Gattermann's method to give the corresponding aldehydes, (Va) and (Vb). The former was treated with i) anhydrous sodium aceate and acetic anhydride ${ }^{10)}$, ii) diethyl malonate ${ }^{(11)}$, and iii) ethyl cyanoacetate to give 6-acetoxy-5-formyl-2-isopropylcoumaran

\footnotetext{
7) J.S.H. Davies, P.A. McCrea, W.L. Norris and G.R. Ramage, J. Chem. Soc., 1950, 3206.

8) J.B.D. Mackenzie, A. Robertson, A. Bushra and R. Towers, 1949, 2057.

9) R. Mozingo, “Organic Syntheses", 26, 77 (1946).

10) J.R. Johnson, "Organic Reactions", 1, 210 (1942).

11) R.O. Clinton and S.C. Laskowski, J. Am. Chem. Soc., 71, 3602 (1949).
}

(Vc), m.p. $97^{\circ} \mathrm{C}, 2^{\prime}$-isopropyl-2',3'-dihydro-3carbethoxy-6,7-furanocoumarin (VIa), m.p. $171 \sim 2^{\circ} \mathrm{C}$ and $2^{\prime}$-isopropyl-2', $3^{\prime}$-dihydro-3-cyano-6,7-furanocoumarin (VIb), m.p. $207 \sim 8^{\circ} \mathrm{C}$, respectively. Hydrolysis of the compounds (VIa or VIb), however, was not fruitfull; VIa was decomposed to $\mathrm{Va}$ with $4 \%$ aqueous sodium hydroxide and not hydrolyzed with $2 \mathrm{~N}$ hydrochloric acid. Concerning to the nitril (VIb), the result of hydrolysis with acid or alkali was almost the same as in the case of VIa, but when heated at $100^{\circ} \mathrm{C}$ for an hour in concentrated sulfuric acid and followed by hydrolysis of the intermediate acid amide with sodium nitrite solution ${ }^{12)}$, the nitril produced a small amount of 2'-isopropyl-2', $3^{\prime}$-dihydro-3carboxy-6,7-furanocoumarin (VIc), m.p. $211^{\circ} \mathrm{C}$. Consequently, the coumaran (Va) was treated with malonic acid in a mixture of pyridine and aniline for 20 hours at room temperature $^{13)}$ to give the carboxylic acid (VIc) in good yield. ( \pm )-Desoxynodakenetin (VId) was obtained by decarboxylation of the acid (VIc) with sodium bisulfite and potassium hydroxide $^{13,14)}$. Hydrogenation of ( \pm )-deoxynodakenetin over platinum catalyst gave desoxydihydrooreoselone showing m.p. $115 \sim 6^{\circ} \mathrm{C}$, the same melting point reported in literature $^{3,4)}$. On the other hand, the coumaran (Vb) was treated with malonic acid in the same way to give the carboxylic acid (VIe), and decarboxylation of this acid gave ( \pm )nodakenetin ${ }^{15}$ ) (or ( \pm )-marmesin) melting at $153 \sim 4^{\circ} \mathrm{C}$. The infrared spectrum $(10 \%$ in chloroform) of the compound is identical with that of natural $(+)$-marmesin. Optical resolution of the acid (VIe) with brucine gave (-)-carboxylic acid $\left([a]_{\mathrm{D}}^{17}-94^{\circ}\right.$ (in chloroform), m.p. $241^{\circ} \mathrm{C}$ ) and (+)-carboxylic acid $\left([a]_{\mathrm{D}}^{17}+91^{\circ}\right.$ (in chloroform),

\footnotetext{
12) F. G. Mann and T.W. G. Porter, J. Chme. Soc., 1945, 751.

13) R. Adams and T.E. Bockstahler, J. Am. Chem. Soc., 74, 5346 (1952).

14) R. Adams and J. Mathieu, J. Am. Chem. Soc., 70, 2120 (1948)

15) F.E. King, J.R. Housley, and T.J. King, J. Chem. Soc., 1954.
} 
m.p. $\left.236 \sim 7^{\circ} \mathrm{C}\right)$. When these optical active acids were decarboxylated, (-)-nodakenetin $\left([a]_{\mathrm{D}}^{18}-22.6^{\circ}\right.$ (in chloroform), m.p. 186.5 $\left.7^{\circ} \mathrm{C}\right)$ and (+)-marmesin $\left([a]_{\mathrm{D}}^{18}+24.5^{\circ}\right.$ (in chloroform), m.p. $188 \sim 9^{\circ} \mathrm{C}$ ) were obtained respectively. The infrared spectra $(\mathrm{KBr}$ tablet) of these two compounds were identical in every detail and also with that of natural $(+)$-marmesin.

\section{EXPERIMENTAL}

6-Benzyloxycoumarone-2-carboxylic Acid (IIb). 2-Hy droxy-4-benzyloxybenzaldehyde (Ib) (11 g), ethyl bromomalonate $(\mathbf{1 4} \mathrm{g})$, anhydrous potassium carbonate $(7 \mathrm{~g})$ and methyl ethyl ketone $(15 \mathrm{ml})$ were mixed together and refluxed for 5 hours on a steam bath. Then the solvent was distilled off, and after the addition of water the residue was acidified with dilute hydrochloric acid and extracted with ether. After removal of ether, the residue was dissolved in alcoholic potash (alcohol $40 \mathrm{ml}$, potassium hydroxide $4 \mathrm{~g}$ ), and refluxed on a steam bath for an hour. After concentration, the residue was dissolved in water and acidified with dilute hydrochloric acid. The colorless crystals were collected, washed with water and dried, m.p. $192^{\circ} \mathrm{C}$. Yield $11.8 \mathrm{~g}(92 \%)$.

Methylation of 6-benzyloxycoumarone-2-carboxylic acid $(1.3 \mathrm{~g})$ was carried out in usual manner using diazomethane. The product was crystallized from methanol to give colorless needles $(1.3 \mathrm{~g})$, m.p. $112^{\circ} \mathrm{C}$.

The methylation was also carried out with methanol and sulfuric acid, and the same methyl ester was obtained.

6-Benzyloxy-2-( $\alpha$-hydroxyisopropyl)-coumarone (III). A solution of methyl 6-benzyloxy-coumarone-2-carboxylate (IIa) $(6 \mathrm{~g})$ in ether $(300 \mathrm{ml})$ was gradually added to methyl magnesium iodide solution (from $3.3 \mathrm{~g}$ of magnesium and $18 \mathrm{~g}$ of methyl iodide in $50 \mathrm{ml}$ of ether) under vigorous stirring and cooling with ice water. The yellow solution was heated under reflux on a steam bath for 20 minutes, cooled with ice water, and treated with dilute hydrochloric acid. The residue was dissolved in benzene $(20 \mathrm{ml})$, passed through aluminum oxide column and eluted with benzene $(200 \mathrm{ml})$. The benzene eluate was evaporated and about $200 \mathrm{mg}$ of colorless needles were obtained, m.p. $58 \sim 61^{\circ} \mathrm{C}$, the structure of which was not established yet. Then the column was eluted with a mixed solvent $(500 \mathrm{ml})$ of benzene and ethyl acetate
(3:1), and the eluate was evaporated to give a pale yellow oil, $4.2 \mathrm{~g}(70 \%)$. This oil was not crystallized, but the characteristic $\mathrm{OH}$-absorption band $\left(3300 \mathrm{~cm}^{-1}\right)$ was clearly observed.

6-Hydroxy-2-isopropylcoumaran (IVa). Hydrogenation of the oily coumarone (III) $(2 \mathrm{~g})$ in ethanol (20 $\mathrm{ml})$ over $5 \%$ palladium charcoal catalyst $(1.5 \mathrm{~g})$ gave 6-hydroxy-2-isopropylcoumaran, after absorbing almost exact 3 moles of hydrogen. This product was purified by distillation in vacuum (b.p. $108 \sim 110^{\circ} \mathrm{C} /$ $0.4 \mathrm{~mm}$ ) and crystallized from hexane to give colorless rhombic prisms, m.p. $79^{\circ} \mathrm{C}$. Yield $1.2 \mathrm{~g}(95 \%)$.

2-Isopropyl-5-formyl-6-hydroxycoumaran (Va). A mixture of 2-isopropyl-6-hydroxycoumaran (IVa) (5 g), zinc cyanide $(10 \mathrm{~g})$, aluminum chloride $(2 \mathrm{~g})$ and anhydrous ether $(150 \mathrm{ml})$ was saturated with dry hydrogen chloride gas under stirring and cooling with ice water for two hours. The resulting reddish orange colored solution was allowed to stand for a day at room temperature. After addtion of more ether $(100 \mathrm{ml})$ and standing for an hour, the upper ethereal layer was decanted off. The reddish viscous oil was washed with ether and heated with water $(100 \mathrm{ml})$ for an hour on a steam bath. The solid was filtered, washed with water and dried. The crude product was crystallized from ethanol to give $3.6 \mathrm{~g}(62 \%)$ of colorless needles, m.p. $101^{\circ} \mathrm{C}$. Anal. Found: C, 70.07; H, 6.85 . Calcd. for $\mathrm{C}_{12} \mathrm{H}_{14} \mathrm{O}_{3}$ : C, 69.88; $\mathrm{H}, 6.84 \%$.

2-Isopropyl-5-formyl-6-acetoxycoumaran ( $\mathrm{Vc}$ ). A mixture of the foregoing aldehyde (Va) $(500 \mathrm{mg})$, anhydrous sodium acetate $(\mathbf{l} \mathrm{g})$ and acetic anhydride $(5 \mathrm{ml})$ was heated for eight hours in an oil bath at $170 \sim 80^{\circ} \mathrm{C}$. After having been diluted with water, the solution was extracted with ether and the ethereal solution was washed with water and dilute sodium hydroxide. On evaporation of ether, the crude coumaran obtained was recrystallized from methanol to give $430 \mathrm{mg}(75 \%)$ of colorless prisms, m.p. $97^{\circ} \mathrm{C}$. Anal. Found: C, 67.73; H, 6.50. Calcd. for $\mathrm{C}_{14} \mathrm{H}_{18} \mathrm{O}_{4}$ : C, $67.65 ; \mathrm{H}, 6.64 \%$.

2'-Isopropyl-2', $3^{\prime}$ - dihydro- 3 - carbethoxy - 6 , 7 -furanocoumarin (VIa). A mixture of the aldehyde (Va) $(1.2 \mathrm{~g})$, ethyl malonate $(900 \mathrm{mg})$, absolute alcohol $(20 \mathrm{ml})$ and piperidine $(2 \mathrm{ml})$ was refluxed for six hours. After cooling the reaction product was filtered and crystallized from ethanol, pale yellow needles, m.p. $172^{\circ} \mathrm{C}$. Yield $1.4 \mathrm{~g}(78 \%)$. Anal. Found: C, 67.51; $\mathrm{H}, 6.05$. Calcd. for $\mathrm{C}_{17} \mathrm{H}_{18} \mathrm{O}_{5}$ : C, 67.54; $\mathrm{H}, 6.00 \%$.

$2^{\prime}$-Isopropyl-2' $\mathbf{3}^{\prime}$-dihydro-3-cyano-6,7-furanocoumarin 
(VIb). A mixture of the aldehyde (Va) (1.2 g), ethyl cyanoacetate $(0.7 \mathrm{~g})$ and absolute ethanol $(20 \mathrm{ml})$ was treated as described above. The product was crystallized from ethanol to give $1.2 \mathrm{~g}(81 \%)$ of yellow needles, m.p. $207 \sim 8^{\circ} \mathrm{C}$. Anal. Found: N, 5.56. Calcd. for $\mathrm{C}_{15} \mathrm{H}_{13} \mathrm{O}_{3} \mathrm{~N}: \mathrm{N}, 5.49 \%$.

Hydrolysis of Carbethoxyfuranocoumarin (VIa). The coumarin VIa was refluxed with $4 \%$ aqueous sodium hydroxide for two hours, acidified with hydrochloric acid and extracted with ether. When the residue was crystallized from ethanol, colorless plate melting at $101^{\circ} \mathrm{C}$ was obtained. It showed no melting point depression with 2-isopropyl-5-formyl-6-hydroxycoumaran.

2'-Isopropyl-2', 3'-dihydro-3-carboxy-6,7-furanocoumarin (VIc). A mixture of dry malonic acid $(2 \mathrm{~g})$, pyridine $(5 \mathrm{ml})$ and 3 drops of aniline was warmed under stirring on steam bath until the acid was dissolved. To the warm solution was added $1.2 \mathrm{~g}$ of the above aldehyde (Va). The mixture became yellow and viscous. It was allowed to stand for 20 hours at room temperature. After acidification with $50 \mathrm{ml}$ of $2 \mathrm{~N}$ hydrochloric acid, the yellow solid was separated, dried and crystallized from ethanol to give $2 \mathrm{~g}(87 \%)$ of yellow needles, m.p. $211 \sim 1.5^{\circ} \mathrm{C}$. Anal. Found: C, 65.90; $\mathrm{H}, 5.27$. Calcd. for $\mathrm{C}_{15} \mathrm{H}_{14} \mathrm{O}_{5}: \mathrm{C}, 65.69 ; \mathrm{H}$, $5.15 \%$.

( \pm )-Desoxynodakenetin(VId). A mixture of the above coumarin (VIc) $(650 \mathrm{mg})$ and $20 \%$ aqueous sodium bisulfite solution $(5.6 \mathrm{ml})$ was boiled for 30 minutes under vigorous stirring. To the solution was added $4.5 \mathrm{ml}$ of $50 \%$ aqueous solution of potassium hydroxide, and the mixture was boiled for ten minutes and cooled in a freezing mixture. Dropwise addition of $6 \mathrm{ml}$ of concentrated hydrochloric acid produced an yellow precipitate, which was collected after further two hours of cooling. The precipitate was washed twice with water and dried. Recrystallization from ethanol gave colorless needles, m.p. $131 \sim 1.5^{\circ} \mathrm{C}$, yield $380 \mathrm{mg}$ (79\%). Anal. Found: C, 73.04; H, 6.38. Calcd. for $\mathrm{C}_{14} \mathrm{H}_{14} \mathrm{O}_{3}:$ C, $73.02 ; \mathrm{H}, 6.13 \%$.

Desoxydihydrooreoselone. A solution of desoxynodakenetin $(400 \mathrm{mg})$ in glacial acid $(15 \mathrm{ml})$ was shaken with Adams' platinum oxide in the presence of hydrogen for 30 minutes. After separation of the catalyst, the solution was diluted and extracted with ether. The solvent was removed and the product was recrystallized from hexane to give $320 \mathrm{mg}(79 \%)$ of colorless flakes, m.p. $115 \sim 6^{\circ} \mathrm{C}$. Anal. Found: C, 72.75;

\section{H, 6.64. Calcd. for $\mathrm{C}_{14} \mathrm{H}_{18} \mathrm{O}_{3}$ : C, 72.39; $\mathrm{H}, 6.94 \%$.}

2-(o-Hydroxyisopropyl)-6-hydroxycoumaran (IVb). The coumarone (III) $(2.8 \mathrm{~g})$ in ethanol $(25 \mathrm{ml})$ was shaken with $5 \%$ palladium charcoal catalyst $(1.5 \mathrm{~g})$ in the presence of hydrogen for 8 hours. After separation of the catalyst and removal of the solvent, the product was recrystallized from ethyl acetate-hexane to give colorless prisms, m.p. $158 \sim 9^{\circ} \mathrm{C}$, yield $1.7 \mathrm{~g}(88 \%)$. Anal. Found: C, 68.06; $\mathrm{H}, 7.23$. Calcd. for $\mathrm{C}_{11} \mathrm{H}_{14} \mathrm{O}_{3}$ : C, $68.02 ; \mathrm{H}, 7.27 \%$.

2-( $\alpha$-Hydroxyisopropyl)-5-formyl-6-hydroxycoumaran (Vb). A mixture of the coumaran (IVb) $(1 \mathrm{~g})$, zinc cyanide $(2 \mathrm{~g})$, aluminum chloride $(100 \mathrm{mg})$ and anhydrous ether $(150 \mathrm{ml})$ was saturated with dry hydrogen chloride gas under stirring and cooling in a freezing mixture. The reaction mixture was allowed to stand for a day at room temperature. After addition of ether $(100 \mathrm{ml})$ and standing for an hour, the upper ethereal layer was removed. The residue was washed with ether and heated with water $(100 \mathrm{ml})$ for an hour on a steam bath. After an insoluble substance was filtered off in a hot state, the filtrate was cooled in an ice bath. The product was recrystallized from water to give colorless needles, m.p. $117 \sim 8^{\circ} \mathrm{C}$. Yield $620 \mathrm{mg}(54 \%)$. Anal. Found: C, $64.79 ; \mathrm{H}, 6.52$. Calcd. for $\mathrm{C}_{12} \mathrm{H}_{14} \mathrm{O}_{4}: \mathrm{C}, 64.85 ; \mathrm{H}, 6.35 \%$.

$2^{\prime}$ - ( $\alpha$-Hydroxyisopropyl) -2', $3^{\prime}$ - dihydro-3-carboxy - 6,7furanocoumarin (VIe). A mixture of dry malonic acid $(960 \mathrm{mg})$, pyridine $(5 \mathrm{ml})$ and 3 drops of aniline was warmed under stirring on a steam bath until the acid was dissolved. To the warm solution was added $1.4 \mathrm{~g}$ of the above aldehyde $(\mathrm{Vb})$ and the mixture was treated in the same way as the above coumarin (VIc). The product was recrystallized from methanol to give $1.1 \mathrm{~g}(61 \%)$ of yellow needles, m.p. $223 \sim 4^{\circ} \mathrm{C}$. Anal. Found: $\mathrm{C}, 61.89 ; \mathrm{H}, 4.96$. Calcd. for $\mathrm{C}_{15} \mathrm{H}_{14} \mathrm{O}_{8}: \mathrm{C}$, $62.06 ; \mathrm{H}, 4.86 \%$.

( \pm )-Nodakenetin (( \pm )-Marmesin) (VIf). Decaboxylation of the carboxylic acid (VIe) $(200 \mathrm{mg}$ ) was completed with sodium bisulfite and $50 \%$ aqueous potassium hydroxide as in the case of $( \pm)$-desoxymarmesin. Recrystallization from methanol gave colorless needles, m.p. $153 \sim 4^{\circ} \mathrm{C}$, yield $120 \mathrm{mg}(71 \%)$. Anal. Found: C, 68.17; H, 5.77. Calcd. for $\mathrm{C}_{14} \mathrm{H}_{14} \mathrm{O}_{4}$ : C, $68.28 ; \mathrm{H}, 5.73 \%$.

$(-)$-Nodakenetin and (+)-Marmesin. A mixture of the carboxylic acid (VIe) (1.1 g) and brucine (1.7 g) in methanol $(20 \mathrm{ml})$ was boiled for two minutes and allowed to stand over night at room temperature. 
After removal of methanol, the residue was dissolved in water, boiled for two minutes and allowed to stand over night at room temperature. The product (m.p. $158^{\circ} \mathrm{C}$, decomp.) was filtered off and decomposed with $2 \mathrm{~N}$-hydrochloric acid. The acid was recrystalliezd three times from methanol to give yellow needles, $240 \mathrm{mg}$ (m.p. $236 \sim 7^{\circ} \mathrm{C},[\alpha]_{\mathrm{D}}^{17}+91^{\circ}$ (in chloroform)). Anal. Found: C, 61.92; H, 4.86. Calcd. for $\mathrm{C}_{15} \mathrm{H}_{14} \mathrm{O}_{6}$ : $\mathrm{C}, 62.06 ; \mathrm{H}, 4.86 \%$. On the other hand, the filtrate was treated with $2 \mathrm{~N}$ hydrochloric acid in the same way as above to give $280 \mathrm{mg}$ of colorless needles, m.p. $241^{\circ} \mathrm{C}$ (from methanol), $[\alpha]_{D}^{17}-94^{\circ}$ (in chloroform). Anal. Found: C, 61.75; H, 5.04 . Calcd. for $\mathrm{C}_{15} \mathrm{H}_{14} \mathrm{O}_{8}$ : C, 62.06; $\mathrm{H}, 4.86 \%$.

These acids were decarboxylated by treating with sodium bisulfite and $2 \mathrm{~N}$ potassium hydroxide to give (+) -marmesin, m.p. $188 \sim 9^{\circ} \mathrm{C}$ (from ethanol), $[\alpha]_{\mathrm{D}}^{18}$ $+24.5^{\circ}$ (in chloroform). Anal. Found: C, 68.12; $\mathbf{H}$, 5.82. Calcd. for $\mathrm{C}_{14} \mathrm{H}_{14} \mathrm{O}_{4}: \mathrm{C}, 68.28 ; \mathrm{H}, 5.73 \%$, and (-) -nodakenetin, m.p. $186.5 \sim 7^{\circ} \mathrm{C}$ (from benzene), $[\alpha]_{\mathrm{D}}^{18}-22.6^{\circ}$ (in chloroform). Anal. Found: C, 68.38; $\mathrm{H}, 5.76 \%$. Calcd. for $\mathrm{C}_{14} \mathrm{H}_{14} \mathrm{O}_{4}$ : C, 68.28; $\mathrm{H}, 5.73 \%$, respectively.

Acknowledgements. The authors wish to express their sincere thanks to Professor A. Chatterjee, University College of Science, Calcutta, for her kind supply of natural marmesin and to Professor T. Mitsui, Kyoto University, for microanalysis. 